\title{
Civilisations
}

Revue internationale d'anthropologie et de sciences

humaines

44 | 1997

Les peuples des forêts tropicales

\section{Situation des peuples indigènes des forêts denses humides}

\section{Pierre Grenand}

\section{(2) OpenEdition \\ Journals}

Édition électronique

URL : http://journals.openedition.org/civilisations/1603

DOI : 10.4000/civilisations. 1603

ISSN : 2032-0442

\section{Éditeur}

Institut de sociologie de l'Université Libre de Bruxelles

\section{Édition imprimée}

Date de publication : 1 janvier 1997

Pagination : 32-35

ISBN : 2-87263-122-4

ISSN : 0009-8140

Référence électronique

Pierre Grenand, «Situation des peuples indigènes des forêts denses humides », Civilisations [En ligne], 44 | 1997, mis en ligne le 29 juin 2009, consulté le 20 avril 2019. URL : http://journals.openedition.org/ civilisations/1603 ; DOI : 10.4000/civilisations.1603 
- SITUATION RES PEUPLES NDIGÈnES

\section{DES FORETTS DENSES HUMIDES}

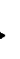

Pierre GRENAND 
Penchons-nous sur les rapports qui existent entre les Etats-nations et les populations forestières qui vivent sur leur territoire. Les situations seront différentes selon les trois continents.

L'Afrique forestière est, aujourd'hui, constituée de peuples indigènes dont certains sont, au moins pour partie, à la tête des États-nations. Cela n'empêche pas les mouvements de migrants, bien que pour ce qui est des zones forestières, les affrontements sont moins forts qu'ailleurs.

En Asie forestière, nous sommes face à des peuples conquérants, comme les Javanais ou les Malais, qui dominent l'ensemble des autres populations. Il existe aussi des cas, comme en Irian Jaya, où des populations étatisées, ici les Indonésiens, n'ont fait que remplacer les Européens, créant des situations néo-coloniales, liées à des enjeux macro-économiques et encore plus tendues qu'auparavant.

L'Amérique du Sud forestière enfin, est partagée entre des républiques indếpendantes globalement dirigées par les descendants des peuples colonisateurs, ce qui fait que, pour les Amérindiens, la situation n'a pas fondamentalement changé et qu'ils demeurent des peuples politiquement dominés même s'ils tendent de plus en plus à organiser des contre-pouvoirs.
Pour ce qui est du statut juridique des populations indigènes, nous sommes face à trois situations:

- l'État-nation ne reconnaît pas les populations indigènes qui vivent sur son territoire; aucun statut n'a besoin de leur être accordé, puisqu'elles n'existent pas;

- l'État-nation n'éprouve pas le besoin de reconnaître ses populations indigènes en tant que cultures homogènes mais il admet qu'elles constituent un "problème» national. La parade est alors d'accorder aux individus la qualité de citoyen, ce qui, ipso facto, casse toute chance d'aboutir aux revendications culturelles ou foncières de ces communautés;

- l'État-nation reconnaît l'existence sur son territoire de populations autochtones enracinées dans le temps-long. Il leur accorde au moins dans un premier temps un statut particulier, par exemple celui de mineurs légaux, qui peut s'avérer être, à court terme, un carcan. Néanmoins ce statut ambigu est depuis trois ou quatre décennies, le point de départ vers une législation à la fois plus soucieuse du respect des Droits de l'Homme et du respect des cultures.

Autrement dit, il est bien délicat de définir la situation la moins mauvaise pour les populations indigènes. Dans le troisième cas, la réalité quotidienne, bien souvent, dément dans les faits les dispositions légales qu'un statut national accorde 
aux indigènes. C'est alors le travail des associations indigènes et indigénistes de faire respecter le statut. On peut citer en exemple le Brésil où depuis le Maréchal Rondon (début de ce siècle), la réalité est en constante violation des différents statuts de l'Indien, de type évolutif, qui ont déjà été imaginés.

L'important n'est donc pas de savoir s'il existe ou non un statut des populations indigènes, mais bien d'avoir présent à l'esprit qu'un statut ne vaut que s'il est appliqué.

Examinons maintenant la situation territoriale des populations indigènes forestières qui ont été l'objet de notre colloque. Là encore, trois cas de figure peuvent être rencontrés:

- elles dominent «écologiquement» un territoire vaste et surtout continu, sur lequel elles règnent presque sans partage. C'est le cas de la NouvelleGuinée;

- elles vivent entremêlées avec des populations qui partagent des valeurs différentes. C'est une situation que l'on peut qualifier de maillage, avec, dans l'ensemble, un territoire à se partager encore vaste, ou, à tout le moins, suffisant;

- elles sont confinées dans des territoires, le plus souvent mais pas toujours, exsangues, en des nucleus noyés au milieu d'une population allogène dominante.

L'attitude générale des États-nations face au type d'occupation territoriale des populations indigènes forestières est pratiquement partout identique : alors que la recherche scientifique est aujourd hui quasi unanime à parler de leur excellente adaptation au milieu naturel et de la viabilité de leur agriculture, l'essartage est partout violemment combattu. Accusé d'être non productif, mangeur de terre et destructeur de forêt, on lui oppose une agriculture permanente sensée devenir la panacée au nom d'une inéluctabilité du progrès tout à fait fantasmatique. Cette agriculture qu'on leur demande d'adopter n'est pas seulement faite de plantes de subsistance, mais encore de cultures de rente destinées à l'exportation, telles le café, le cacao, le coton... Comprenons bien que l'adoption exclusive de ce type d'agriculture n'a jamais signifié autre chose que la paupérisation de ceux qui la pratiquent, devenus incapables de se nourrir et dépendants des cours d'un marché mondial dont ils ignorent les mécanismes.

Les populations forestières autochtones sont souvent considérées, par un public non averti, comme étant vagabondes, mobiles, nomades. On les accusent d'occuper plus d'espace que nécessaire et la politique des États-nations consiste bien souvent à les concentrer sur des territoires exsangues dont la superficie est déterminée sans aucune espèce de calcul de leurs besoins, ou encore le long de routes qu'ils sont sensés animer. On ne cherche, en fait, à les rassembler que pour donner de l'espace à des populations allogènes, à des activités économiques prédatrices ou plus banalement à «rationaliser» l'occupation de l'espace en calquant des schémas d'aménagement du territoire hérités du Monde occidental.

Prenons l'exemple du Brésil : les populations indigènes présentées comme obstacle au développement national, ne réclament, toutes ensemble, 
que 16\% du territoire de l'Amazonie. C'est derrière ce chiffre dérisoire que l'on voudrait cacher les 84\% restant au Brésil pour triompher de son impéritie sociale et économique. Autrement dit, les problèmes de cette vaste région ne sont pas à imputer à la présence des Indiens, mais bien plutôt à une pitoyable gestion, à un mauvais partage des richesses, à l'absence de démocratie.

Le message que nous voudrions faire passer est le suivant : les populations indigènes forestières ne sont pas un obstacle au développement des pays dans lesquels elles vivent et toute déclaration dans ce sens ne ressort que du fantasme. 